\title{
Spillover Bias in Diversity Judgment
}

\author{
David P. Daniels ${ }^{1} \quad$ Margaret A. Neale Lindred L. Greer \\ Stanford University
}

\footnotetext{
${ }^{1}$ Graduate School of Business, Stanford University, 655 Knight Way, Stanford, CA 94305, United States. Please direct all correspondence to ddanielsestanford.edu. The authors wish to thank Peter Belmi, Drew Carton, Jennifer Dannals, Johanna He, and Taylor Phillips for helpful comments, and Christine Hart for providing assistance with our experiments. The corresponding author would like to thank the National Science Foundation and the Stanford Graduate School of Business for generous financial support.
}

(C) 2016. This manuscript version is made available under the Elsevier user license http://www.elsevier.com/open-access/userlicense/1.0/ 
Spillover Bias in Diversity Judgment Authors Blinded For Peer Review Affiliations Blinded For Peer Review 


\begin{abstract}
Diversity research has long assumed that individuals' perceptions of diversity are accurate, consistent with normative theories of judgments in economics and decision theory. We challenge this assumption. In six experiments, we show that when there is more diversity along one dimension (e.g., race, clothing color), people also perceive more diversity on other dimensions (e.g., gender, skill) even when this cannot reflect reality. This spillover bias in diversity judgment leads to predictable errors in decision making with economic incentives for accuracy, and it alters support for affirmative action policies in organizations. Spillover bias in diversity judgment may help explain why managerial decisions about groups often appear to be suboptimal and why diversity scholars have found inconsistent associations between objective diversity and team outcomes.
\end{abstract}

Keywords: spillover bias; diversity; judgment; decision making 


\section{Spillover Bias in Diversity Judgment}

\section{Introduction}

Diversity sharpens the opportunities and the challenges for groups, organizations, and societies (Apfelbaum, Phillips, \& Richeson, 2014; Levine, Apfelbaum, Bernard, Bartelt, Zajac, \& Stark, 2014; March \& Simon, 1958; Page, 2007b). As diversity increases, groups can access a larger variety of information sets and decision processes with which to accomplish their objectives (e.g. Hackman, 2002; LiCalzi \& Surucu, 2012; Lorenz, Rauhut, Schweitzer, \& Helbing, 2011; Page, 2007a; Wuchty, Jones, \& Uzzi, 2007). However, at the same time, greater differences in preferences and beliefs can make it harder for groups to overcome agency and coordination problems (e.g. Cronin \& Weingart, 2007; Klein \& Harrison, 2007; Van den Steen, 2010). Thus, diverse and homogeneous groups have different strengths and weaknesses (e.g. Mannix \& Neale, 2005). This means that optimal managerial decisions about creating and managing groups can require accurate judgments of diversity - i.e., unbiased assessments of levels of diversity. ${ }^{1}$ Conversely, if judgments of diversity are systematically biased (e.g. Kahneman, Slovic, \& Tversky, 1982), some managerial decisions about groups will be wrong (e.g. Bazerman \& Moore, 2013).

In diversity research, perceptions of diversity have long been assumed to be essentially accurate (with some exceptions that we discuss below). While perceived diversity has played a central role in definitions and theories of diversity (e.g. van Knippenberg, De Dreu, \& Homan, 2004; Mannix \& Neale, 2005; Williams \& O’Reilly, 1998), these theories have usually been tested with data on objective diversity (cf. Shemla, Meyer, Greer, \& Jehn, 2016). Similarly, neoclassical models in economics and decision theory (e.g. Luce \& Raiffa, 1957; Mas-Collel, Whinston, \& Green, 1995; von Neumann \& Morgenstern, 1947) would assume that diversity judgments, like other judgments, are unbiased. ${ }^{2}$ These assumptions are surprising in light of the

\footnotetext{
${ }^{1}$ In this paper, we use the terms "judgment," "perception," "assessment," and "estimate" interchangeably.

${ }^{2}$ Research in behavioral economics, with its central focus on biases in judgments and decisions, has been careful to provide objective diversity information explicitly (e.g. Niederle, Segal, \& Vesterlund, 2013). However, even this may not be sufficient to ensure that judgments of diversity are unbiased, as the results of Experiment 2 will suggest.
} 
fact that many studies have documented strong biases in human judgment processes, especially when the situation is ambiguous and when the situation includes information that is salient but normatively irrelevant (Kahneman, 2011).

We assert that both of these catalysts for judgment bias - ambiguous situations and the presence of salient but normatively irrelevant information - are likely to characterize the typical formation of diversity judgments. First, when people form judgments of diversity, the definition of "diversity" is usually ambiguous and multidimensional (Bell \& Hartmann, 2007; Harrison \& Klein, 2007; Klein \& Harrison, 2007; Williams \& O’Reilly, 1998); in particular, it is often uncertain exactly which dimensions of diversity are relevant and which dimensions of diversity are irrelevant. For instance, it might seem implausible that in business contexts the definition of “diversity" would include diversity of height, but height diversity does meet a standard definition of diversity in the literature - differences among individuals on any attribute (Mannix \& Neale, 2005; Williams \& O'Reilly, 1998) - and people would certainly be able to form judgments of height diversity if they were asked to do so. Second, when people are forming judgments of a certain type of diversity, there virtually always exists diversity information that is salient but normatively irrelevant: information about other types of diversity. If diversity judgment processes involve heuristics that place some weight on irrelevant diversity information (Kahneman, Slovic, \& Tversky, 1982), this could produce a systematic bias in diversity judgment.

This paper challenges traditional assumptions about the accuracy of diversity judgments. We argue that diversity judgments on a single dimension will often be biased towards diversity levels on other salient dimensions. In six experiments, we find evidence of such a spillover bias in diversity judgment. We demonstrate that when there is more diversity along one dimension (e.g., race, clothing color), people also perceive more diversity on other dimensions (e.g., gender, skill) even when this cannot reflect reality. Experiment 1 shows that an increase in objective racial diversity causes an increase in judgments of gender diversity, using a face perception paradigm where objective gender diversity is held constant. Experiment 2 demonstrates that an increase in even a "minimal" type of diversity (e.g. Loyd, Wang, Phillips, \& Lount, 2012) - randomly 
assigned shirt colors - can cause an increase in judgments of gender diversity among members of real interacting teams who have just completed a substantial team task together (and where objective gender diversity was also held constant). Experiment 3 shows that spillover bias leads to predictable errors in decision making with economic incentives for accuracy; the bias is strong, reversing the decision preferences of about $46 \%$ of participants. Experiment 4 demonstrates that programming skill diversity can spill over to distort judgments of racial/ethnic diversity. Experiment 5 documents additional evidence of spillover bias using a larger sample size for higher statistical power. Experiment 6 shows that spillover bias can alter people's support for affirmative action policies in organizations.

\section{Contribution}

Our investigation of spillover bias has implications for three strands of research: managerial decision making, diversity judgment processes, and research on diversity and performance. First, if managers believe a team is diverse when it is actually homogeneous (or vice-versa), this can lead to errors in managerial decision making, such as giving a homogeneous group a task that requires a diverse set of perspectives, knowledge, and/or skills. Spillover bias may thus help explain why managerial decisions about teams often appear to be suboptimal (e.g. Bazerman \& Moore, 2013). Second, while most diversity research has implicitly assumed that perceptions of diversity are accurate, this paper contributes to an emerging literature on the microfoundations of diversity perceptions (e.g. Homan, Greer, Jehn, \& Koning, 2010; Loyd, Wang, Phillips, \& Lount, 2012; Phillips \& Loyd, 2006; Phillips, Mannix, Neale, \& Gruenfeld, 2004; Phillips, Northcraft, \& Neale, 2006; Phillips, Weisbuch, \& Ambady, 2014; Zellmer-Bruhn, Maloney, Bhappu, \& Salvador, 2008) suggesting that people's assessments of diversity may not always be veridical. Third, diversity scholars have not found consistent associations between objective diversity and team outcomes (for overviews, see, e.g. van Dijk, van Engen, \& van Knippenberg, 2012; van Knippenberg \& Schippers, 2007). However, if team outcomes are strongly affected by biased diversity judgments, it does not necessarily follow that team outcomes will be strongly correlated 
with actual levels of diversity. Thus, a better understanding of biases in diversity judgment (such as spillover bias) has the potential to open up new productive and interesting avenues for future research on diversity and outcomes.

\section{Theoretical Framework}

Diversity refers to differences among individuals on any attribute (Mannix \& Neale, 2005; Williams \& O'Reilly, 1998). Managers are often interested in how diverse a team is on a single attribute (e.g. Thomas \& Ely, 1996); e.g., if racial issues are a sensitive and/or performance-related concern in a team, then racial diversity will probably be more important than other types of diversity. In such a case, a manager may wish to estimate how racially diverse the team is. Note that the manager has information about both relevant inputs that should affect the focal judgment, i.e. the team's objective racial diversity configuration (a function of the racial composition of the team), and irrelevant inputs that should not affect the focal judgment, e.g. the team's gender diversity, the team's skill diversity, and so on. If a manager's assessment of diversity on a single attribute (e.g., race) is unbiased, as normative judgment theories in economics and decision theory would predict (Baron, 2004), it will be affected by diversity on the relevant attribute (i.e., race) but completely unaffected by diversity on all irrelevant attributes (e.g., gender, skill).

In contrast to normative (i.e. idealized) judgment processes, behavioral (i.e. human) judgment processes often do take into account inputs that are salient even if they are normatively irrelevant, as has been shown by 40 years of research in psychology and economics (for overviews, see, e.g., Kahneman, 2003, 2011). We propose that managers use heuristics when assessing the level of diversity in their teams. Because of heuristic judgment processes, individuals' judgments of the level of diversity on a single attribute in a group may reveal a spillover bias towards levels of diversity on other salient attributes.

Two prominent heuristics in judgment and decision making which may drive spillover bias are anchoring and representativeness. Suppose managers intuitively use the anchoring heuristic 
when assessing diversity on a single target attribute, such that their judgments are distorted towards salient but irrelevant starting points called anchors (e.g. Chapman \& Johnson, 1999; Epley \& Gilovich, 2006; Tversky \& Kahneman, 1974; Northcraft \& Neale, 1987; Simmons, LeBoeuf, \& Nelson, 2010). When attempting to estimate the level of diversity on a single target attribute, evidence about the levels of diversity on other attributes may come to mind and serve as anchors for the target judgment, thereby distorting the diversity judgment on the target dimension towards levels of diversity on other, irrelevant dimensions. For example, when assessing the amount of gender diversity in a team, evidence regarding the amount of racial diversity or skill diversity may come to mind and "pull" a manager's judgment of gender diversity towards their judgments of racial diversity or skill diversity.

Alternatively, assume managers intuitively use the representativeness heuristic when assessing diversity on a single target attribute (e.g. Kahneman \& Frederick, 2002; Tversky \& Kahneman, 1974). Assume further that levels of diversity across different attributes prototypically associated with the idea of diversity - e.g., race/ethnicity and gender (e.g. Mannix \& Neale, 2005) - are positively correlated in individuals' prototype of a group. For example, a racially diverse team might be presumed to be also gender diverse, given that both types of diversity have a strong association with the broader prototype of diversity. (Recent studies support this idea, suggesting that "race is gendered" and "gender is racialized" in people's minds (e.g. Carpinella et al., 2015; Freeman et al., 2013; Galinsky et al., 2013; Johnson et al., 2012; Sesko \& Biernat, 2010). For instance, prototypical Asian faces are viewed as feminine, whereas prototypical Black faces are viewed as masculine (e.g. Johnson et al., 2012; Sesko \& Biernat, 2010). Conversely, prototypical feminine faces are viewed as White, whereas prototypical masculine faces are viewed as Black (e.g. Carpinella et al., 2015).) This means that if managers were to rely on the representativeness heuristic when making diversity judgments, perceptions of gender and racial diversity would be likely to spill over onto each other. For example, if a manager knows a team has a high level of racial diversity, our two assumptions imply that the manager's judgments of (e.g.) gender diversity would likely be also high. 
Thus, if diversity judgment processes include the anchoring heuristic and/or the representativeness heuristic, then an assessment of diversity on a single attribute may take into account both the actual amount of diversity on the relevant attribute and the amounts of diversity on irrelevant attributes. Consequently, judged diversity on a target attribute may not accurately reflect the actual level of diversity on that target attribute. We refer to any systematic distortions produced by such a judgment process as spillover bias because information about irrelevant types of diversity "spills over" to distort judgments of diversity or decisions based on diversity judgments.

\section{Experiment 1}

\section{Participants}

We recruited 1578 adults to participate in an online study in exchange for payment via Amazon Mechanical Turk (906 male, 666 female, 6 other; $M_{\text {age }}=31.5$ ). ${ }^{3}$

\section{Procedure}

Participants were randomly assigned to one of eight conditions in a 4 (objective racial diversity configuration) $\times 2$ (diversity judgment order) between-subjects design.

First, participants viewed a group of three faces, which we randomly assigned to represent one of four objective racial diversity configurations: White/White/White, Black/White/White, Asian/White/White, or Black/White/Asian. Face images were obtained from Johnson, Freeman, and Pauker (2012), who used the computer program FaceGen Modeler to create "novel faces that are characteristic of the observed features for particular groups." In all four configurations, the first face was male, the second face was female, and the third face was male.

Second, participants rated the extent to which they viewed the group as racially diverse and

\footnotetext{
${ }^{3}$ Following the disclosure guidelines recommended by Simmons, Nelson, \& Simonsohn (2011), in all experiments, we report how we determined our sample size, all data exclusions (if any), all manipulations, and all measures in the study. In Experiment 1, we chose a sample size of 1600 in advance; we analyze results for the 1578 participants who completed the entire survey. In this and subsequent experiments, for the purposes of calculating mean age, we drop any participants who reported an "age" greater than 1000 or less than 10 .
} 
gender diverse using 2-item scales, with each item ranging from 1 ("Strongly Disagree”) to 7 ("Strongly Agree"). For example, the 2 items assessing racial diversity were "There is a lot of RACIAL/ETHNIC DIVERSITY in this group" and "This group is RACIALLY/ETHNICALLY DIVERSE". Both of the perceived diversity scales were reliable (perceived racial diversity $\alpha=.96$, perceived gender diversity $\alpha=.92$ ). We randomly assigned diversity judgment order: $\left(1^{\text {st }}\right)$ both racial diversity items, $\left(2^{\text {nd }}\right)$ both gender diversity items vs. $\left(1^{\text {st }}\right)$ both gender diversity items, $\left(2^{\text {nd }}\right)$ both racial diversity items. ${ }^{4}$

Finally, we asked participants how many faces they recognized (if any), for demographic information, and for comments about the study.

\section{Results}

As expected, our manipulation of objective racial diversity significantly affected perceived racial diversity $(F(3,1574)=478.9, p=.000)$. All six $t$-test pairwise contrasts were significant (all $p \mathrm{~s}=.000)$ between the White/White/White condition $(M=2.18, S D=1.42)$, the Black/White/White condition $(M=4.61, S D=1.27)$, the Asian/White/White condition $(M=3.99, S D=1.54)$, and the Black/White/Asian condition $(M=5.75, S D=1.19){ }^{5}$

Our primary hypothesis of spillover bias in diversity judgment predicted that an increase in the level of diversity on the "source" diversity attribute will increase judgments of diversity on the "target" diversity attribute. As predicted, our manipulation of objective racial diversity significantly affected perceived gender diversity $(F(3,1574)=3.39, p=.018)$. There was a spillover bias from objective racial diversity to perceived gender diversity, driven by significant differences between the White/White/White condition and the three other conditions, which were not significantly differerent from one another. Specifically, perceived gender diversity was lower in the White/White/White condition $(M=4.12, S D=1.56)$ than in the Black/White/White condition $(M=4.41, S D=1.42)(t(782)=2.75, p=.006)$, the Asian/White/White condition

\footnotetext{
${ }^{4}$ We also included for exploratory purposes a 3-item scale relating to evaluations of hypothetical interactions with the "group" they observed. These results are available upon request.

${ }^{5}$ In all $t$-tests, we use the Satterthwaite approximation for degrees of freedom.
} 
$(M=4.36, S D=1.47)(t(795)=2.21, p=.027)$, and the Black/White/Asian condition $(M=4.41, S D=1.59)(t(795)=2.62, p=.009)$. Thus, consistent with a spillover bias, more racial diversity caused participants to perceive more gender diversity. These patterns are illustrated in Figure 1.

\section{Discussion}

Experiment 1, using a face perception paradigm, showed that an increase in levels of racial diversity caused an increase in judgments of gender diversity, even though actual gender diversity was held constant. This is evidence of a spillover bias in diversity judgment. ${ }^{6}$

These results suggest several further questions. First, a limitation of Experiment 1 is that it involved only hypothetical groups. Does spillover bias also emerge in real in-person group interactions, when members have a chance to get to know one another? Second, participants likely viewed themselves as outsiders vis-à-vis the hypothetical groups. Would spillover bias manifest among people who were actual group members themselves? Third, in principle, spillover bias could be limited to the specific types of diversity we chose to investigate (race and gender). Can spillover bias be generated even by a "minimal" type of diversity (e.g. Loyd, Wang, Phillips, \& Lount, 2012)? If so, it would suggest that spillover bias may not be limited to any particular set of diversity attributes, but rather may be a general property of diversity judgment. Experiment 2 was designed to shed light on these questions.

\footnotetext{
${ }^{6}$ The fact that the results of Experiment 1 were driven by differences between the minimum racial diversity (White/White/White) condition and the other conditions might appear to suggest that maximum homogeneity is particularly distinctive, unusual, or powerful compared to other levels of diversity (Phillips \& Apfelbaum, 2012). However, the results of Experiment 2 are driven by differences between the maximum diversity condition and other conditions, i.e. the opposite of the "asymmetry" documented in Experiment 1. It may be that both minimum diversity and maximum diversity are particularly distinctive, or it may be that neither is. This would be an interesting direction for future research.
} 


\section{Experiment 2}

\section{Participants}

We recruited 300 adults from a dedicated participant pool at Stanford University (150 male, 150 female; $M_{\text {age }}=22.2$ ) to participate in a laboratory experiment in exchange for monetary payment, structuring the recruitment process to ensure that tetrads of 2 men and 2 women could participate simultaneously. $^{7}$

\section{Procedure}

We randomly assigned participants to 4-person teams, conditional on each team having identical gender compositions of 2 men and 2 women. Participants were individually seated at computers and filled out a pre-task questionnaire. They were (truthfully) told they would take a short personality survey, and that "the items on this survey are put into a scientifically validated formula to sort people into meaningful personality groups. You will then be assigned into one of these categories - green, yellow, red, or blue. The experimenter will give you a T-shirt of that color to wear for the rest of the experiment." Despite our mention of a personality survey, we did not explicitly indicate how participants would be assigned to teams for the purposes of the experiment; in fact, we randomly assigned teams to wear colored T-shirts in one of three configurations: all 4 members wear the same color T-shirt ("minimum shirt color diversity"), 3 members wear one color T-shirt and 1 member wears a different color T-shirt ("moderate shirt color diversity"), and every member wears a different color T-shirt ("maximum shirt color diversity"). ${ }^{8}$

Each team was given the task of completing a group construction project. All of the teams assembled 89 LEGO pieces into a pre-designed figure (Hero Factory Stormer XL, LEGO Item \#6230), closely following the procedure of previous LEGO tasks designed to assess team

\footnotetext{
${ }^{7} \mathrm{We}$ chose a sample size of 300 in advance based on our estimate of the upper bound of recruitment possibilities for the lab. Because such a design would only yield 25 teams for our 3 cell experimental design, we decided to not randomize diversity judgment order (as done in Experiment 1) to increase the precision of our estimates.

${ }^{8}$ For colors, we used blue, red, yellow, and green, which we randomly assigned conditional on the assigned level of shirt color diversity.
} 
coordination (e.g. Staats, Milkman, \& Fox, 2012). Teams were initially shown an instruction sheet that included a picture of the fully assembled LEGO figure. Teams were tasked with assembling the LEGO pieces "as quickly and accurately as possible," and were told that the fastest team would be awarded a bonus of $\$ 100$, evenly split four ways. Next, teams were given a LEGO set and asked to begin assembly. Their efforts were timed. When a team finished an attempt, a research assistant checked their assembly attempt against a correctly assembled Hero Stormer. If their assembly attempt did not exactly match the correctly assembled figure, then the team was informed that corrections were necessary and it continued working. When the assembly attempt did exactly match the correctly assembled figure, the timer was stopped and the time recorded. After completing the team task, participants were individually seated at computers and filled out a post-task questionnaire. In the questionnaire, participants rated the extent to which they viewed the group as diverse with respect to T-shirt color, gender diverse, and diverse overall using 3-item scales. For example, the 3 items assessing diversity with respect to T-shirt color were "How diverse was your team with respect to T-SHIRT COLOR?" ranging from 1 ("Not at all") to 7 ("Extremely"), "How different were the members of your team from one another with respect to T-SHIRT COLOR?" ranging from 1 ("Not at all”) to 7 (“Extremely"), and "How much variety was there among your team members with respect to T-SHIRT COLOR?" ranging from 1 ("None") to 7 ("A lot"). All of the 3 perceived diversity scales were reliable (perceived shirt color diversity $\alpha=.91$, perceived gender diversity $\alpha=.84$, perceived overall diversity $\alpha=.90){ }^{9}$ Finally, we asked participants for demographic information.

\section{Results}

We analyzed data at the individual level using hierarchical linear models with team-level random effects. For "pairwise contrasts," we used hierarchical linear models comparing only two

\footnotetext{
${ }^{9}$ After participants responded to the 9 perceived diversity items, but before we asked participants for demographic information, we included for exploratory purposes (on separate successive screens) six scales from the management literature designed to measure coordination (adapted from Mohr \& Spekman (1994)), trust (de Jong \& Elfring, 2010), information elaboration (Homan, van Knippenberg, van Kleef, \& De Dreu, 2007), relationship quality (adapted from Rispens, Greer, Jehn, \& Thatcher (2011)), satisfaction and liking (Jehn, 1995), and conflict (Jehn, 1995). These results are available upon request.
} 
conditions at a time, using an indicator variable for one of the conditions.

As expected, our manipulation of objective shirt color diversity significantly affected perceived shirt color diversity $\left(\chi^{2}(2)=206.53, p=.000\right)$. All three pairwise contrasts were significant, between the minimum shirt color diversity $(M=1.57, S D=.93)$ and both the moderate shirt color diversity condition $(M=2.54, S D=.84)(t(50)=6.27, p=.000)$ and the maximum shirt color diversity condition $(M=6.17, S D=.94)(t(50)=29.99, p=.000)$ and between the latter two $(t(50)=28.38, p=.000)$.

Our hypothesis of spillover bias predicted that an increase in the level of shirt color diversity would increase judgments of diversity with respect to gender. Consistent with this hypothesis, our manipulation of objective shirt color diversity significantly affected perceived gender diversity $\left(\chi^{2}(2)=18.55, p=.000\right)$. Once again, participants revealed a spillover bias this time, from objective shirt color diversity to perceived gender diversity, driven by significant differences between the maximum shirt color diversity condition and the two other conditions. Specifically, perceived gender diversity was higher in the maximum shirt color diversity condition $(M=5.89, S D=1.07)$ than in the moderate shirt color diversity condition $(M=5.03, S D=1.32)(t(50)=5.05, p=.000)$ and the minimum shirt color diversity condition $(M=5.22, S D=1.49)(t(50)=3.37, p=.001)$; the latter two conditions were not significantly different from one another $(t(50)=.892, p=.377)$. These patterns are illustrated in Figure 2 .

We also measured perceived overall diversity. Our manipulation of objective shirt color diversity significantly affected perceived overall diversity $\left(\chi^{2}(2)=42.80, p=.000\right)$. This was driven by significant differences between the maximum shirt color diversity condition and the other two conditions. Specifically, perceived overall diversity was higher in the maximum shirt color diversity condition $(M=5.39, S D=1.16)$ than in the moderate shirt color diversity condition $(M=4.26, S D=1.21)(t(200)=6.72, p=.000)$ and the minimum shirt color diversity condition $(M=4.53, S D=1.06)(t(200)=5.49, p=.000)$; the latter two conditions were not significantly different from one another $(t(200)=1.64, p=.102){ }^{10}$

\footnotetext{
${ }^{10}$ At the team level, we measured task completion time $(M=19$ minutes and 15 seconds, $S D=4$ minutes and 30 seconds). (Team task completion time was not successfully recorded for 6 out of 75 teams.) Our manipulation of
} 


\section{Discussion}

Experiment 2 demonstrated that members of a team can reveal a spillover bias in diversity judgment even after substantial face-to-face interaction in an incentivized team task. Since diversity in shirt colors was randomly assigned, was neither demographically nor functionally important, and was still sufficient to generate a spillover bias, it seems likely that spillover bias is a reasonably general property of diversity judgment.

In Experiment 3, we tested whether spillover bias in diversity judgment could affect decision making with economic incentives for accuracy. If we observe a spillover bias in decision making, it would be important for two reasons. First, it would suggest that spillover bias does not only emerge when 7-point response scales are used. Second, it would suggest that spillover bias can distort the actions that people take.

\section{Experiment 3}

\section{Participants}

We recruited 100 adults to participate in an online study in exchange for payment via Amazon Mechanical Turk (60 male, 40 female; $\left.M_{\text {age }}=32.52\right){ }^{11}$

\section{Procedure}

Participants were informed that they had the opportunity to obtain a cash bonus of up to $\$ 1$ (Amir, Rand, \& Gal, 2012) by earning points, which were converted to a cash at a rate of 1 point $=1$ cent. Then, they read a description of two software companies. Company A had skills in 8 programming languages, while Company B had skills in 9 programming languages (including all of Company A's languages). Thus, Company A always had lower programming skill diversity, while Company B always had higher programming skill diversity. We randomly assigned one company to have high demographic diversity (with respect to both racial diversity and gender objective shirt color diversity did not significantly affect task completion time $(F(2,66)=1.17, p=.318)$.

${ }^{11} \mathrm{We}$ chose a sample size of 100 in advance. 
diversity) and the other company to have low demographic diversity (with respect to both racial diversity and gender diversity). Participants in the Company A has high demographic diversity,

Company $B$ has low demographic diversity condition read: ${ }^{12}$

Company A has a very high level of racial and ethnic diversity (including White, Black, Asian, and Hispanic people) and a very high level of gender diversity (including an even mix of men and women). Company A has skills in the following programming languages: C\#, SQL, Java, PHP, C++, Javascript, Ruby, Python. ${ }^{13}$

Company B has a very low level of racial and ethnic diversity (including White people only) and a very low level of gender diversity (including men only). Company B has skills in the following programming languages: Java, Javascript, C\#, PHP, C++, Python, C, SQL, Ruby.

Participants in the Company A has low demographic diversity, Company B has high demographic diversity condition read:

Company A has a very low level of racial and ethnic diversity (including White people only) and a very low level of gender diversity (including men only). Company A has skills in the following programming languages: C\#, SQL, Java, PHP, C++, Javascript, Ruby, Python.

Company B has a very high level of racial and ethnic diversity (including White, Black, Asian, and Hispanic people) and a very high level of gender diversity (including an even mix of men and women). Company B has skills in the following programming languages: Java, Javascript, C\#, PHP, C++, Python, C, SQL, Ruby.

On the next screen, all participants then made a binary decision:

Suppose you are a manager who wants to acquire whichever company has the most diversity in terms of programming language skills, defined as the number of programming languages that the company knows.

Which company will you choose to acquire? (If you pick the right answer, you will get 100 points.)

Since Company B had skills in a strictly larger set of programming languages than Company A, Company B had higher programming skill diversity; thus, Company B was always

\footnotetext{
${ }^{12} \mathrm{We}$ also randomized sentence order with respect to whether the irrelevant source diversity was described first and the target diversity was described second, or vice-versa.

${ }^{13}$ All programming languages were taken from a list of top programming languages at https://web.archive.org/web/20150208024242/http://mashable.com/2015/01/18/programming-languages-2015/
} 
the correct choice. ${ }^{14}$

On the next screen, participants were asked three follow-up questions: "Which company had more racial/ethnic diversity?", "Which company had more gender diversity?", and "Which company had more programming language skill diversity?"

Finally, we asked participants for demographic information and comments about the study.

\section{Results}

If there is a spillover bias in diversity judgment, then when the optimal choice is a function of programming skill diversity but not of demographic diversity, the probability of a suboptimal choice will be greater when there are larger differences between the levels of programming skill diversity and the levels of demographic diversity. This is indeed what we found. Recall that Company B was always the optimal choice, since it always had higher programming skill diversity than Company A. When Company B had a lower level of demographic diversity than Company A, only $37.3 \%$ of participants chose it; however, when Company B had a higher level of demographic diversity than Company A, $83.7 \%$ of participants chose it $\left(\chi^{2}(1)=20.54, p=.000\right)$. Put differently, while most people selected the suboptimal choice in the former condition (when Company B had high diversity with respect to programming skills but low diversity with respect to demographics), most people selected the optimal choice in the latter condition (when Company B had high diversity across both dimensions). Thus, participants' choices were strongly distorted by a spillover bias in diversity judgment. These patterns are illustrated in Figure 3.

In addition, when Company A had a higher level of demographic diversity than Company B, $95.9 \%$ of participants judged Company A to have more racial/ethnic diversity than company B $\left(\chi^{2}(1)=39.51, p=.000\right), 93.9 \%$ of participants judged Company A to have more gender

\footnotetext{
${ }^{14}$ Note that while participants were aware there was money at stake during the entire task, they did not know while reading about Company A and Company B that a single piece of information (i.e., which company had higher programming skill diversity) would turn out to be essential to making an optimal (i.e. point-earning) decision. We believe this feature of our experimental design captures an important aspect of many (though certainly not all) managerial decisions: managers often know there is money at stake without knowing in advance exactly which pieces of information will be important for later decision making.
} 
diversity $\left(\chi^{2}(1)=36.00, p=.000\right)$, and $77.6 \%$ of participants judged Company A to have more programming language skill diversity $\left(\chi^{2}(1)=13.80, p=.000\right)$. However, when Company A had a lower level of demographic diversity than Company B, only $7.8 \%$ of participants judged Company A to have more racial/ethnic diversity than company $\mathrm{B}\left(\chi^{2}(1)=34.59, p=.000\right)$, only $3.9 \%$ of participants judged Company A to have more gender diversity $\left(\chi^{2}(1)=41.49, p=.000\right)$, and only $52.9 \%$ of participants judged Company A to have more programming language skill diversity $\left(\chi^{2}(1)=0.08, p=.779\right)$. Moreover, for all three diversity judgments, tests for equality of proportions across the two conditions reject the null hypothesis at the $5 \%$ level. Thus, participants' diversity judgments revealed a spillover bias from demographic diversity to programming language skill diversity.

\section{Discussion}

Experiment 3 provided additional evidence of spillover bias in diversity judgment - this time, from demographic diversity to programming language skill diversity. Moreover, Experiment 3 showed that spillover bias in diversity judgment can strongly distort the decisions that people make, even when they have economic incentives for accuracy.

A potential alternative explanation for Experiment 3's results is that participants might have believed that people from different demographic groups would have developed skills in different programming languages, and thus that an increase in demographic diversity should result in a real increase in objective programming language skill diversity. While we think this possibility is unlikely, we decided to conduct an even sharper test of spillover bias. In Experiment 4, we tested for a spillover bias from programming skill diversity to racial/ethnic diversity and gender diversity, since it is impossible for an increase in programming skill diversity to result in a real increase in racial/ethnic diversity or gender diversity. 


\section{Experiment 4}

\section{Participants}

We recruited 450 adults to participate in an online study in exchange for payment via Amazon Mechanical Turk (247 male, 199 female, 4 other; $\left.M_{\text {age }}=34.3\right) .{ }^{15}$

\section{Procedure}

Participants were randomly assigned to one of four conditions in a 2 (programming skill diversity level) $\times 2$ (diversity judgment order) between-subjects design. First, participants read a scenario about a startup team, which we randomly assigned to have high programming skill diversity or low programming skill diversity.

All participants read the following:

"Imagine you are the CEO of a startup company that creates software "apps" for smartphones. There are 5 software programmers in your programming group, depicted here:

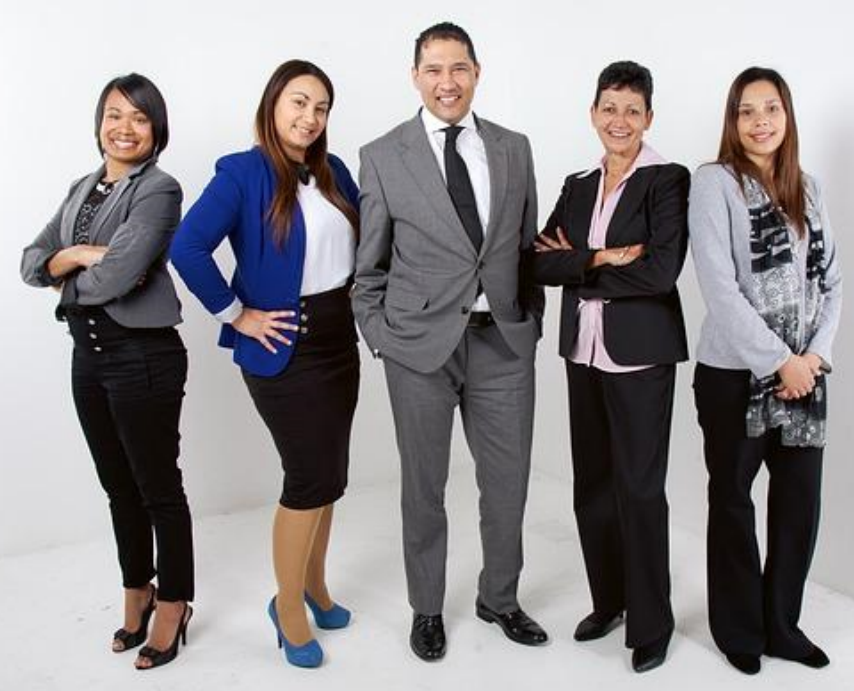

There are 5 different types of smartphones: Alpha, Beta, Gamma, Delta, and Epsilon. All 5 smartphones are made by different hardware manufacturers, who are in fierce market competition. For each of the 5 manufacturers, there is a chance it will go out of business by the time you would release your smartphone apps."

\footnotetext{
${ }^{15}$ We chose a sample size of 450 in advance.
} 
Then, participants in the high programming skill diversity ethnic diversity condition read:

“As CEO of your startup, you know that your company's group of software programmers specialize in the following programming skills:

Specialization in Alpha: 1 programmer

Specialization in Beta: 1 programmer

Specialization in Gamma: 1 programmer

Specialization in Delta: 1 programmer

Specialization in Epsilon: 1 programmer"

Meanwhile, participants in the low programming skill diversity condition read that all 5 programmers specialized in the same programming skill (randomly assigned), e.g.:

“As CEO of your startup, you know that your company's group of software programmers specialize in the following programming skills:

Specialization in Alpha: 5 programmers

Specialization in Beta: 0 programmers

Specialization in Gamma: 0 programmers

Specialization in Delta: 0 programmers

Specialization in Epsilon: 0 programmers"

On the next screen, participants rated the extent to which they viewed the group as programming-skill diverse, gender diverse, and racially/ethnically diverse using 2-item scales, with each item ranging from 1 ("Strongly Disagree") to 7 ("Strongly Agree"). The wording of the items followed Experiment 1 . We randomly assigned diversity judgment order as follows: $\left(1^{\text {st }}\right)$ both programming skill diversity items, $\left(2^{\text {nd }}\right)$ both racial/ethnic diversity items, $\left(3^{\text {rd }}\right)$ both gender diversity items vs. $\left(1^{\text {st }}\right)$ both racial/ethnic diversity items, $\left(2^{\text {nd }}\right)$ both gender diversity items, $\left(3^{\text {rd }}\right)$ both programming skill diversity items.

Finally, we asked participants for demographic information and comments about the study.

\section{Results}

As expected, participants judged the group to have significantly more programming skill diversity when the group had a high level of programming skill diversity $(M=5.46, S D=1.78)$ 
than when the group had a low level of programming skill diversity $(M=1.69, S D=1.28)$ $(t(406)=25.82, p=.000)$.

More strikingly, participants judged the group to have significantly more racial/ethnic diversity when the group had a high level of programming skill diversity $(M=5.16, S D=1.35)$ than when the group had a low level of programming skill diversity $(M=4.85, S D=1.47)$ $(t(445)=2.29, p=.022)$.

Participants did not judge the group to have significantly more gender diversity when the group had a high level of programming skill diversity $(M=4.14, S D=1.78)$ than when the group had a low level of programming skill diversity $(M=3.93, S D=1.77)$ $(t(448)=1.24, p=.217)$. We will return to this null result in the general discussion section when we discuss evidence for theoretical mechanisms underlying spillover bias.

\section{Discussion}

Experiment 4 suggests that a spillover bias can occur for any two dimensions of diversity (i.e. demographic or non-demographic diversity dimensions) if the source diversity dimension is sufficiently salient when people are forming judgments about the target diversity dimension.

In Experiment 5, we tested for a spillover bias using a larger sample size for higher statistical power.

\section{Experiment 5}

\section{Participants}

We recruited 2454 adults to participate in an online study in exchange for payment via Amazon Mechanical Turk (1232 male, 1213 female, 9 other; $\left.M_{\text {age }}=33.73\right){ }^{16}$

\footnotetext{
${ }^{16} \mathrm{We}$ decided in advance to terminate invitations when 2400 adults had completed the survey; an additional 54 adults had already been invited and completed the survey shortly thereafter. We discarded data from one participant who reported an age of 17.
} 


\section{Procedure}

Participants were randomly assigned to one of four conditions in a 2 (racial/ethnic diversity level) $\times 2$ (diversity judgment order) between-subjects design. First, participants read a scenario about a startup team, which we randomly assigned to have high racial/ethnic diversity or low racial/ethnic diversity.

Participants in the low racial/ethnic diversity condition read:

"Imagine you are the CEO of a startup company that creates software "apps" for smartphones.

You are writing a diversity report about your startup company's large group of software programmers. Here is the information you need to base it on:

Racial Diversity:

The group of software programmers is $99 \%$ White and 1\% Black."

Participants in the high racial/ethnic diversity condition read:

"Imagine you are the CEO of a startup company that creates software "apps" for smartphones.

You are writing a diversity report about your startup company's large group of software programmers. Here is the information you need to base it on:

Racial Diversity:

The group of software programmers is $51 \%$ White and $49 \%$ Black."

Next, all participants read the following:

"Gender Diversity:

The group of software programmers is $60 \%$ men and $40 \%$ women.

Programming Skill Diversity:

There are 5 different types of smartphones: Alpha, Beta, Gamma, Delta, and Epsilon. The group's level of programming skill diversity is determined by the following information:

Specialization in Alpha: $70 \%$ of programmers

Specialization in Beta: $25 \%$ of programmers

Specialization in Gamma: $5 \%$ of programmers

Specialization in Delta: 0\% of programmers

Specialization in Epsilon: 0\% of programmers" 
Then, on the next screen, participants rated the extent to which they viewed the group as programming-skill diverse, gender diverse, and racially/ethnically diverse using 2-item scales, with each item ranging from 1 ("Strongly Disagree”) to 7 ("Strongly Agree"). The wording of the items followed Experiment 1 . We randomly assigned judgment order as follows: $\left(1^{\text {st }}\right)$ both programming skill diversity items, $\left(2^{\text {nd }}\right)$ both gender diversity items, $\left(3^{\text {rd }}\right)$ both racial/ethnic diversity items vs. $\left(1^{\text {st }}\right)$ both racial/ethnic diversity items, $\left(2^{\text {nd }}\right)$ both gender diversity items, $\left(3^{\text {rd }}\right)$ both programming skill diversity items.

Finally, we asked participants for demographic information and comments about the study.

\section{Results}

As expected, participants judged the group to have significantly more racial/ethnic diversity when the group had a high level of racial/ethnic diversity $(M=4.84, S D=1.65)$ than when the group had a low level of racial/ethnic diversity $(M=1.68, S D=1.27)$ $(t(2313)=53.27, p=.000)$.

More strikingly, participants judged the group to have significantly more gender diversity when the group had a high level of racial/ethnic diversity $(M=4.91, S D=1.27)$ than when the group had a low level of racial/ethnic diversity $(M=4.50, S D=1.38)$ $(t(2434)=7.75, p=.000)$.

Participants did not judge the group to have significantly more programming skill diversity when the group had a high level of racial/ethnic diversity $(M=3.37, S D=1.44)$ than when the group had a low level of racial/ethnic diversity $(M=3.31, S D=1.35)$

$(t(2444)=1.03, p=.301)$. Again, we will return to this null result in the general discussion section when we discuss evidence for theoretical mechanisms underlying spillover bias.

\section{Discussion}

Experiments 1-5 document strong evidence of a spillover bias in diversity judgment. In our final study, Experiment 6, we conducted an exploratory investigation into whether spillover bias 
might influence support for organizational policies related to diversity. We focused on how spillover bias in diversity judgment might distort evaluations of gender-based affirmative action policies. In particular, suppose spillover bias causes people to mistakenly believe that gender diversity is higher than it actually is. On the one hand, this might lead people to think that affirmative action policies should be less necessary because there are already many women in the organization and/or in the labor supply of potential employees. On the other hand, this might lead people to think that more potential women employees exist who would benefit from a stronger affirmative action policy, and thus that affirmative action policies should be more necessary.

\section{Experiment 6a}

\section{Participants}

We recruited 398 adults to participate in an online study in exchange for payment via Amazon Mechanical Turk (207 male, 191 female; $\left.M_{\text {age }}=34.01\right){ }^{17}$

\section{Procedure}

Participants were randomly assigned to one of four conditions in a 2 (racial/ethnic diversity level) $\times 2$ (diversity judgment order) between-subjects design.

In the low racial/ethnic diversity condition, participants read the following (adapted from Lowery, Unzueta, Knowles, \& Goff (2006)):

"Strathmore International is a consulting firm operating in the Midwestern United States. It specializes in facilitation of export financing, tourism development, and environmental management.

The workforce at Strathmore International is $99 \%$ White and 1\% Black.

Several years ago, an internal audit found that Strathmore's hiring practices unfairly disadvantaged women. To correct for this unintentional bias Strathmore adopted an

\footnotetext{
${ }^{17}$ We decided in advance to terminate invitations when 400 adults had been invited.
} 
affirmative action policy whereby extra efforts are made to get women to apply for positions at the firm. This policy, however, does not consider gender in the final selection decision."

In the high racial/ethnic diversity condition, participants read the following:

"Strathmore International is a consulting firm operating in the Midwestern United States. It specializes in facilitation of export financing, tourism development, and environmental management.

The workforce at Strathmore International is $51 \%$ White and $49 \%$ Black.

Several years ago, an internal audit found that Strathmore's hiring practices unfairly disadvantaged women. To correct for this unintentional bias Strathmore adopted an affirmative action policy whereby extra efforts are made to get women to apply for positions at the firm. This policy, however, does not consider gender in the final selection decision."

Then, on the next screen, participants rated the extent to which they viewed Strathmore as racially/ethnically diverse and gender diverse using 2-item scales, with each item ranging from 1 ("Strongly Disagree") to 7 ("Strongly Agree"). The wording of the items followed Experiment 1. Both scales were reliable (perceived racial/ethnic diversity $\alpha=.97$, perceived gender diversity $\alpha=.95)$. We randomly assigned diversity judgment order: $\left(1^{\text {st }}\right)$ both racial/ethnic diversity items, $\left(2^{\text {nd }}\right)$ both gender diversity items vs. $\left(1^{\text {st }}\right)$ both gender diversity items, $\left(2^{\text {nd }}\right)$ both racial/ethnic diversity items. Finally, we asked participants for demographic information and comments about the study.

On the next screen, we asked participants two questions from Lowery et al. (2006): "How do you feel about Strathmore's affirmative action policy?" (1 = strongly oppose, $7=$ strongly support) and then "How fair/unfair do you think Strathmore's affirmative action policy is?" $(1=$ not fair at all, $7=$ very fair). 


\section{Results}

As expected, participants perceived significantly more racial/ethnic diversity in the high racial/ethnic diversity condition $(M=5.08, S D=1.50)$ than in the low racial/ethnic diversity condition $(M=1.74, S D=1.47),(t(398)=22.43, p=.000)$. Furthermore, consistent with a spillover bias from racial/ethnic diversity to gender diversity, participants perceived significantly more gender diversity in the high racial/ethnic diversity condition $(M=3.04, S D=1.45)$ than in the low racial/ethnic diversity condition $(M=2.39, S D=1.36),(t(397)=4.64, p=.000)$.

Participants reported more support for Strathmore's affirmative action policy in the high racial/ethnic diversity condition $(M=4.27, S D=1.65)$ than in the low racial/ethnic diversity condition $(M=3.94, S D=1.62),(t(398)=1.97, p=.049)$. Participants reported that Strathmore's affirmative action policy was more fair in the high racial/ethnic diversity condition $(M=4.29, S D=1.71)$ than in the low racial/ethnic diversity condition $(M=3.82, S D=1.63),(t(398)=2.81, p=.005)$. These results are consistent with the hypothesis that spillover bias can alter support for affirmative action policies.

\section{Discussion}

The results of Experiment $6 \mathrm{a}$ are consistent with the hypothesis that a spillover bias in diversity judgment from racial/ethnic diversity to gender diversity led people to believe that many women employees (and/or potential women employees) would benefit from a gender-based affirmative action policy, generating increased support for the gender-based affirmative action policy. In principle, however, it is possible that another mechanism besides spillover bias could have generated this result. As a falsification test, therefore, we re-ran Experiment $6 \mathrm{a}$ as Experiment 6b, with one change: we asked participants to evaluate Strathmore's affirmative action policy before (rather than after) the diversity judgment questions. This change should decrease the weight of people's diversity judgments in their evaluations of the affirmative action policy. Thus, if spillover bias is causing the change in evaluations of Strathmore's affirmative action policy, there should be a smaller effect (or even no effect) of the racial/ethnic diversity 
manipulation on support for the gender-based affirmative action policy in Experiment $6 \mathrm{~b}$.

\section{Experiment 6b}

\section{Participants}

We recruited 390 adults to participate in an online study in exchange for payment via Amazon Mechanical Turk (218 male, 172 female; $\left.M_{\text {age }}=34.11\right){ }^{18}$

\section{Procedure}

The procedure was identical to Experiment 6a, except the two questions about the organization's affirmative action policy were asked before (rather than after) the diversity judgment questions.

\section{Results}

As expected, participants perceived significantly more racial/ethnic diversity in the high racial/ethnic diversity condition $(M=5.24, S D=1.45)$ than in the low racial/ethnic diversity condition $(M=1.80, S D=1.45),(t(387)=23.41, p=.000)$. Furthermore, consistent with a spillover bias from racial/ethnic diversity to gender diversity, participants perceived significantly more gender diversity in the high racial/ethnic diversity condition $(M=3.20, S D=1.44)$ than in the low racial/ethnic diversity condition $(M=2.54, S D=1.42),(t(388)=4.55, p=.000)$.

In line with our prediction, while participants reported directionally more support for Strathmore's affirmative action policy in the high racial/ethnic diversity condition $(M=4.25, S D=1.78)$ than in the low racial/ethnic diversity condition $(M=4.09, S D=1.69),(t(388)=0.87, p=.39)$, this was not statistically significant. Similarly, while participants reported that Strathmore's affirmative action policy was directionally more fair in the high racial/ethnic diversity condition $(M=4.22, S D=1.87)$ than in the low racial/ethnic diversity condition $(M=4.02, S D=1.82),(t(388)=1.04, p=.30)$, this was again not statistically significant.

\footnotetext{
${ }^{18}$ We decided in advance to terminate invitations when 400 adults had been invited.
} 
Overall, the results of Experiment 6b suggest that spillover bias was indeed causing the change observed in evaluations of Strathmore's affirmative action policy in Experiment 6a.

\section{General Discussion}

In this paper, we have challenged traditional assumptions that individuals' perceptions of diversity are accurate. We argued that diversity judgments on a single dimension will often be biased towards diversity levels on other salient dimensions, because of the anchoring heuristic and the representativeness heuristic. In six experiments, we found evidence of such a spillover bias in diversity judgment and decision making. All Experiments 1-6 demonstrated that when there is more diversity along one dimension (e.g., race, clothing color), people also perceive more diversity on other dimensions (e.g., gender, skill) even when this cannot reflect reality. This spillover bias in diversity judgment occurs even after substantial face-to-face interaction in an incentivized team task (Experiment 2); it leads to predictable errors in decision making with economic incentives for accuracy (Experiment 3); and it can alter support for affirmative action policies in organizations (Experiment 6).

\section{Which Heuristic?}

In our theory section, we argued that spillover bias in diversity judgment could be caused by either the anchoring heuristic or the representativeness heuristic. How might we conduct a preliminary investigation into whether a particular instance of spillover bias is driven by the anchoring heuristic or by the representativeness heuristic? It is well known that in judgment processes governed by the anchoring heuristic, the history of recently constructed judgments e.g. answers to previous survey questions - can strongly affect which cues are available in memory, often providing an external anchor that distorts subsequent judgments (e.g. Fox \& Weber, 2002; Mochon \& Frederick, 2013; Moore, 1999). In contrast, we are not aware of any theory or evidence suggesting that judgment processes driven by the representativeness heuristic will be affected by the history of recently constructed judgments. 
Thus, we consider the possibility that the anchoring heuristic and the representativeness heuristic are likely to generate a spillover bias in diversity judgment under two different sets of conditions. Specifically, the anchoring heuristic should generate a spillover bias between any two perceived diversity dimensions, such that the judgment of a focal type of diversity is distorted towards other types of diversity that are salient in one's mind at the time the judgment is made. This implies that a spillover bias will be most likely to occur when participants form a judgment of the irrelevant "source" diversity immediately before they form a judgment of the "target" diversity, and spillover bias will be less likely to occur if diversity judgments are formed in a different order - i.e., if people are not directed to focus on an external anchor of one form of diversity before judging other forms. In contrast, for some types of diversity, the representativeness heuristic might still distort diversity judgments even in the absence of anchoring; in particular, in cases where the "source" and "target" diversity dimensions are both prototypically associated with the idea of "diversity" (e.g. gender and race/ethnicity), the representativeness heuristic should generate a spillover bias in diversity judgment whether or not there is an external anchor to generate a spillover bias via the anchoring heuristic.

Alongside our primary manipulations that tested for a spillover bias in diversity judgment, in Experiments 1, 4, 5, and 6 we also manipulated the order in which participants formed diversity judgments. If a particular instance of spillover bias was driven primarily by the anchoring heuristic, then we should observe a spillover bias when participants form a judgment of the irrelevant "source" diversity immediately before they form a judgment of the "target" diversity, but less (or no) spillover bias for other judgment orders. However, if a particular instance of spillover bias was driven by the representativeness heuristic, then we should observe a spillover bias regardless of judgment order.

In Table 1, for each experiment, we summarize the theoretical mechanisms proposed to drive spillover bias in diversity judgment, alongside the empirical evidence of spillover bias for each judgment order. There is some preliminary evidence for the two patterns predicted by the anchoring and representativeness heuristics. In particular, in the three "anchoring" rows with 
judgment order manipulations, there is a significant or marginally significant spillover bias for "source first, target second" judgments but no significant spillover bias for "target first, source second" judgments. Meanwhile, in the four "representativeness" rows with judgment order manipulations, seven out of eight tests reveal a spillover bias that is significant at the $5 \%$ level. ${ }^{19}$ However, we acknowledge that this mechanism evidence is preliminary. While we believe it is suggestive of the possibility that anchoring and representativeness are driving spillover bias in diversity judgment, it is far from conclusive. Further research should more fully explore the mechanisms behind spillover bias, ideally using even larger samples, to increase our understanding of what is very likely a multiply-determined phenomenon.

Table 1

Overview of Theoretical Mechanisms and Empirical Evidence for Spillover Bias in Diversity Judgment, Experiments 1-6

\begin{tabular}{|c|c|c|c|c|c|}
\hline Experiment & $\begin{array}{c}\text { Source } \\
\text { diversity } \\
\text { dimension }\end{array}$ & $\begin{array}{c}\text { Target } \\
\text { diversity } \\
\text { dimension }\end{array}$ & $\begin{array}{l}\text { Primary theoretical } \\
\text { mechanism producing } \\
\text { spillover bias } \\
\text { in diversity judgment }\end{array}$ & $\begin{array}{l}\text { Directional } \\
\text { spillover bias } \\
\text { if source first, } \\
\text { target second? }\end{array}$ & $\begin{array}{l}\text { Directional } \\
\text { spillover bias } \\
\text { if target first, } \\
\text { source second? }\end{array}$ \\
\hline 1 & Racial/Ethnic & Gender & Representativeness & Yes $(p=.107)$ & Yes $(p=.007)$ \\
\hline 2 & "Minimal" & Gender & Anchoring & Yes $(p=.000)$ & \\
\hline 3 & "Demographic" & $\begin{array}{l}\text { Programming } \\
\text { Skill }\end{array}$ & Anchoring & Yes $(p=.018)$ & \\
\hline 4 & $\begin{array}{c}\text { Programming } \\
\text { Skill }\end{array}$ & Racial/Ethnic & Anchoring & Yes $(p=.005)$ & Yes $(p=.677)$ \\
\hline 4 & $\begin{array}{l}\text { Programming } \\
\text { Skill }\end{array}$ & Gender & Anchoring & Yes $(p=.037)$ & No $(p=.773)$ \\
\hline 5 & Racial/Ethnic & Gender & Representativeness & Yes $(p=.000)$ & Yes $(p=.000)$ \\
\hline 5 & Racial/Ethnic & $\begin{array}{l}\text { Programming } \\
\text { Skill }\end{array}$ & Anchoring & Yes $(p=.071)$ & No $(p=.701)$ \\
\hline $6 a$ & Racial/Ethnic & Gender & Representativeness & Yes $(p=.005)$ & Yes $(p=.000)$ \\
\hline $6 b$ & Racial/Ethnic & Gender & Representativeness & Yes $(p=.001)$ & $\operatorname{Yes}(p=.003)$ \\
\hline
\end{tabular}

\footnotetext{
${ }^{19}$ Plausibly due to sample size limitations, judgment order was not a significant moderator of spillover bias in diversity judgment (all interaction $p$-values greater than or equal to .1) despite the differences in $p$-values observed for different judgment orders in Table 1.
} 


\section{Theoretical Implications}

Our introduction of the phenomenon of spillover bias in diversity judgment has implications for three strands of research: managerial decision making, diversity judgment processes, and research on diversity and performance. First, if managers believe a team is diverse when it is actually homogeneous (or vice-versa), this can lead to errors in managerial decision making. For instance, if a manager overestimates the level of demographic diversity on a team, they might allocate too many resources towards team-building exercises and too few resources towards increasing the team's level of diversity. Or, if a manager overestimates the level of skill diversity on a team, the manager might direct a team towards solving new problems when the team instead should be implementing existing solutions (Aggarwal \& Woolley, 2013). Alternatively, if a manager underestimates the level of skill diversity on a team, the manager might give the team too many tasks requiring specialist skills, rather than tasks requiring generalist skills; or, when making hiring decisions, the manager might select too many new generalists, rather than new specialists (Wang \& Murnighan, 2013). Thus, spillover bias may help explain why managerial decisions about teams often appear to be suboptimal (e.g. Bazerman \& Moore, 2013).

In addition, while most diversity research has implicitly assumed that perceptions of diversity are accurate, this paper contributes to an emerging literature on the microfoundations of diversity perceptions (e.g. Homan, Greer, Jehn, \& Koning, 2010; Loyd, Wang, Phillips, \& Lount, 2012; Phillips \& Loyd, 2006; Phillips, Mannix, Neale, \& Gruenfeld, 2004; Phillips, Northcraft, \& Neale, 2006; Phillips, Weisbuch, \& Ambady, 2014; Zellmer-Bruhn, Maloney, Bhappu, \& Salvador, 2008) suggesting that people's assessments of diversity may not always be veridical. Our paper contributes to this line of work in three ways. First, this research has often investigated how individual differences - e.g. in motivations - affect perceptions of diversity (Bauman, Trawalter, \& Unzueta, 2014; Unzueta \& Binning, 2012; Unzueta, Knowles, \& Ho, 2012). In contrast, we investigate how biases in diversity judgment might be revealed across populations, and even in the absence of strong motivational forces. Second, we show that judgments of diversity are not random distortions of actual levels of diversity, but systematic and predictable 
distortions. Third, while virtually all past research has focused on how a judgment of diversity on a single dimension might be different from the actual level of diversity on that single dimension (Shemla et al., 2016), it has neglected the possible interdependence across different dimensions of diversity judgments; examining diversity on a single attribute "may cause analysts to miss the potential impact of other attributes or their interactions" (Lau \& Murnighan, 1998). Overall, because multiple types of diversity will often be salient when people are forming judgments of group diversity, spillover bias suggests that systematic distortions in diversity judgment will be typical rather than unusual.

Finally, diversity scholars have not found consistent associations between objective diversity and team outcomes (for overviews, see, e.g. van Dijk, van Engen, \& van Knippenberg, 2012; van Knippenberg \& Schippers, 2007), which has made progress in research on the relationship between diversity and outcomes more difficult (van Knippenberg \& Schippers, 2007; Mannix \& Neale, 2005; Williams \& O’Reilly, 1998). However, if team outcomes are strongly affected by biased diversity judgments, it does not necessarily follow that team outcomes will be strongly correlated with actual levels of diversity. Thus, if people often reveal a spillover bias in diversity judgment, then the inconsistent associations that have been reported in the literature between actual levels of diversity and team outcomes are not particularly surprising. If researchers do not understand how judgment biases are distorting answers to survey questions about "objective" diversity, "researchers will draw the wrong conclusions" (Mochon \& Frederick, 2013). Conversely, an understanding of biases in diversity judgment has the potential to open up new productive and interesting avenues for future research on diversity and outcomes. Specifically, our investigation of spillover bias in diversity judgment can improve our understanding of judgment processes in teams and organizations and can therefore help improve diversity research by highlighting situations in which objective diversity and perceived diversity are most likely to diverge - namely, when there are different levels of diversity across dimensions. This suggests that the use of objective diversity as a proxy measure for perceived diversity, common in the literature, will be most successful when groups have similar levels of diversity on 
every dimension. It often makes sense to assume perceptions are accurate in the absence of evidence to the contrary, so diversity researchers have historically made the reasonable simplifying assumption that perceived diversity accurately reflects objective diversity (c.f. Shemla et al., 2016). However, after decades of research on diversity, there do not appear to be consistent associations between objective diversity and team outcomes (e.g. van Dijk, van Engen, \& van Knippenberg, 2012; van Knippenberg \& Schippers, 2007). Thus, in light of the evidence in this paper documenting systematic distortions in perceptions of diversity, it may be worth redirecting more research efforts towards investigating how perceived diversity affects team outcomes and how diversity judgments are generated, which might allow us to draw more robust scientific inferences about the outcome consequences of diversity.

More generally, our theoretical account of spillover bias also has implications for the broader literature on judgment and decision making. Our documentation of a spillover bias across dimensions of group diversity suggests the potential existence of spillover bias among any set of judgments that are cognitively "linked" via conceptual uncertainty or ambiguity, relating our account to the classic literature in psychology on halo effects and mental contamination (e.g. Nisbett \& Wilson, 1977; Wilson \& Brekke, 1994). More recently, theoretical and empirical work on inattention has made enormous strides in behavioral science, increasing our understanding of many striking errors in judgment under uncertainty (e.g. Chugh \& Bazerman, 2007; Schkade \& Kahneman, 1998; Simon, 1955) and the consequences of such errors for decision making in economic and social systems (e.g. Brown, Hossain, \& Morgan, 2010; Carroll, Bazerman, \& Maury, 1988; Chetty, Looney, \& Kroft, 2009; DellaVigna \& Pollet, 2009; Halevy \& Chou, 2014; Hirshleifer, Lim, \& Teoh, 2009; Tor \& Bazerman, 2003). We speculate that behavioral insights of similar importance might emerge from an analogous renewed research focus on overattention, perhaps building on a dimensional-weighting model as a formal theoretical framework (e.g. Tversky \& Gati, 1982). 


\section{Limitations and Future Directions}

While our empirical findings were obtained with randomized experiments across different paradigms and participant pools, many questions remain for future work. For instance, it is probably not possible for any laboratory experiment to reproduce the full complexity of actual organizational teams. Thus, future research might complement our laboratory experiments with field experiments in real organizations.

Additionally, in our paper we focus on people's general perceptions of diversity, rather than asking people to give specific counts of the number of diverse members in a team. Given that in Experiments 1 and 2 we did not always find differences between moderate levels of diversity and either maximum diversity (in Experiment 1) or minimum diversity (in Experiment 2), it is possible that people may generally categorize teams as having either "low" or "high" diversity, rather than maintaining a more precise tally of the exact number of diverse individuals in a team. This would align with the idea that people might form a general, broad-stroke image of diversity, particularly with respect to prototypical forms of diversity, which they then apply when judging other forms of diversity. However, there is room for future research to improve our understanding of the similarities and differences between numeric perceptions and more general perceptions of diversity in teams.

Future research could also explore possible moderators of spillover bias. For instance, perhaps spillover bias would strengthen if people were placed under time pressure, as this can increase the likelihood of people relying on heuristics such as representativeness or anchoring. Other moderators might involve the choice environment in which judgments of diversity are made - for example, spillover bias might weaken if people were to evaluate teams jointly (i.e. deciding between Team A vs. Team B) rather than separately (i.e. first evaluating Team A, then evaluating Team B) (Milkman, Chugh, \& Bazerman, 2009).

Finally, as discussed in the previous section, future research should more fully explore the mechanisms that may drive spillover bias in diversity judgment (e.g., the anchoring heuristic and the representativeness heuristic). 


\section{Practical Implications}

From a practitioner standpoint, an understanding of spillover bias might help managers make better decisions about their teams. Because diverse teams and homogeneous teams have different strengths and weaknesses (e.g. Aggarwal \& Woolley, 2013), optimal managerial decisions about teams can require accurate assessments of team diversity. But in the presence of spillover bias, managerial diversity judgments are likely to be systematically wrong. Yet that very systematicity of error also provides the opportunity to "nudge" diversity judgments in the right direction (Thaler \& Sunstein, 2008).

For example, levels of racial and gender diversity are very low among the leaders and engineers of many technology companies (similar to other high-ranking professionals in many organizations - see, e.g., McGinn \& Milkman, 2012), but in other ways these employees are diverse - for example, they hold degrees from many different universities and often have special expertise in different engineering or business areas. ${ }^{20}$ Our theory and findings, particularly Experiment 6, suggest that managers who wish to increase support for diversity-related policies in their organizations may wish to draw attention to any way in which their organizations are diverse - not necessarily in terms of race and gender. Because of spillover bias in diversity judgment, this may help raise the salience of the women and minority members of the labor force who would benefit from stronger diversity-related policies, and thereby increase support for them.

\footnotetext{
${ }^{20}$ Compare, for example, https://web.archive.org/web/20140629181923/http://www.google.com/diversity/at-google.html (highlighting very low levels of racial and gender diversity) and https://web.archive.org/web/20140714222152/http://www.google.com/about/careers/teams/engineering/ (highlighting high levels of skill diversity).
} 


\section{References}

Aggarwal, I., \& Woolley, A. W. (2013). Do you see what I see? The effect of members' cognitive styles on team processes and errors in task execution. Organizational Behavior and Human Decision Processes, 122(1), 92-99.

Amir, O., Rand, D. G., \& Gal, Y. K. (2012). Economic games on the internet: The effect of \$1 stakes. PloS One, 7(2).

Apfelbaum, E. P., Phillips, K. W., \& Richeson, J. A. (2014). Rethinking the baseline in diversity research: Should we be explaining the effects of homogeneity? Perspectives on Psychological Science, 9(3), 235-244.

Baron, J. (2004). Normative models ofjudgment and decision making. In D. J. Koehler, \& N. Harvey (Eds.) Blackwell handbook of judgment and decision making, (pp. 19-36). London: Blackwell.

Bauman, C. W., Trawalter, S., \& Unzueta, M. M. (2014). Diverse according to whom? Racial group membership and concerns about discrimination shape diversity judgments. Personality and Social Psychology Bulletin, 40(10), 1354-72.

Bazerman, M. H., \& Moore, D. A. (2013). Judgment in Managerial Decision Making. New York: John Wiley and Sons.

Bell, J., \& Hartmann, D. (2007). Diversity in everyday discourse: The cultural ambiguities and consequences of "happy talk". American Sociological Review, 72(1997), 895-914.

Brown, J., Hossain, T., \& Morgan, J. (2010). Shrouded attributes and information suppression: Evidence from the field. The Quarterly Journal of Economics, (May), 859-876.

Carpinella, C. M., Chen, J. M., Hamilton, D. L., \& Johnson, K. L. (2015). Gendered Facial Cues Influence Race Categorizations. Personality and Social Psychology Bulletin, 41(3), 405-419.

Carroll, J., Bazerman, M., \& Maury, R. (1988). Negotiator cognitions: A descriptive approach to negotiators' understanding of their opponents. Organizational Behavior and Human Decision Processes, 370, 352-370.

Chapman, G., \& Johnson, E. (1999). Anchoring, activation, and the construction of values. Organizational Behavior and Human Decision Processes, 79(2), 115-153.

Chetty, R., Looney, A., \& Kroft, K. (2009). Salience and taxation: Theory and evidence. American Economic Review, (pp. 1145-1177).

Chugh, D., \& Bazerman, M. (2007). Bounded awareness: What you fail to see can hurt you. Mind \& Society, 6(1), 1-18.

Cronin, M., \& Weingart, L. (2007). Representational gaps, information processing, and conflict in functionally diverse teams. Academy of Management Review, 32(3), 761-773. 
de Jong, B., \& Elfring, T. (2010). How does trust affect the performance of ongoing teams? The mediating role of reflexivity, monitoring, and effort. Academy of Management Journal, 53(3), $535-549$.

DellaVigna, S., \& Pollet, J. (2009). Investor inattention and Friday earnings announcements. The Journal of Finance, $\operatorname{LXIV(2).}$

Epley, N., \& Gilovich, T. (2006). The anchoring-and-adjustment heuristic: Why the adjustments are insufficient. Psychological Science, 17(4), 311-8.

Fox, C. R., \& Weber, M. (2002). Ambiguity aversion, comparative ignorance, and decision context. Organizational Behavior and Human Decision Processes, 88(1), 476-498.

Freeman, J. B., Nakayama, K., \& Ambady, N. (2013). Interactive effects: Finger in flight reveals parallel categorization across multiple social dimensions. Social Cognition, 31(6), 792-805.

Galinsky, A. D., Hall, E. V., \& Cuddy, A. J. C. (2013). Gendered races: implications for interracial marriage, leadership selection, and athletic participation. Psychological science, 24(4), 498-506.

Hackman, J. R. (2002). Leading teams: Setting the stage for great performances. Boston, MA: Harvard Business School Press.

Halevy, N., \& Chou, E. Y. (2014). How decisions happen: Focal points and blind spots in interdependent decision making. Journal of Personality and Social Psychology, 106(3), $398-417$.

Harrison, D. A., \& Klein, K. J. (2007). What's the Difference? Diversity Constructs As Separation, Variety, or Disparity in Organizations. Academy of Management Review, 32(4), 1199-1228.

Hirshleifer, D., Lim, S., \& Teoh, S. (2009). Driven to distraction: Extraneous events and underreaction to earnings news. The Journal of Finance, 64(5), 2289-2325.

Homan, A., van Knippenberg, D., van Kleef, G. A., \& De Dreu, C. K. (2007). Interacting dimensions of diversity: Cross-categorization and the functioning of diverse work groups. Group Dynamics: Theory, Research, and Practice.

Homan, A. C., Greer, L. L., Jehn, K. A., \& Koning, L. (2010). Believing shapes seeing: The impact of diversity beliefs on the construal of group composition. Group Processes and Intergroup Relations, 13(4), 477-493.

Jehn, K. (1995). A multimethod examination of the benefits and detriments of intragroup conflict. Administrative Science Quarterly.

Johnson, K. L., Freeman, J. B., \& Pauker, K. (2012). Race is gendered: How covarying phenotypes and stereotypes bias sex categorization. Journal of Personality and Social Psychology, 102(1), 116-31. 
Kahneman, D. (2003). Maps of bounded rationality: Psychology for behavioral economics. The American Economic Review, 93(5), 1449-1475.

Kahneman, D. (2011). Thinking, Fast and Slow. New York: Farrar, Straus and Giroux.

Kahneman, D., \& Frederick, S. W. (2002). Representativeness revisited: Attribute substitution in intuitive judgment. In T. Gilovich, D. W. Griffin, \& D. Kahneman (Eds.) Heuristics and biases: The psychology of intuitive judgment, (pp. 49-81). New York: Cambridge University Press.

Kahneman, D., Slovic, P., \& Tversky, A. (1982). Judgment under uncertainty: Heuristics and biases. New York: Cambridge University Press.

Klein, K., \& Harrison, D. (2007). On the diversity of diversity: Tidy logic, messier realities. The Academy of Management Perspectives, (pp. 26-34).

Lau, D., \& Murnighan, J. (1998). Demographic diversity and faultlines: The compositional dynamics of organizational groups. Academy of Management Review, 23(2), 325-340.

Levine, S. S., Apfelbaum, E. P., Bernard, M., Bartelt, V. L., Zajac, E. J., \& Stark, D. (2014). Ethnic diversity deflates price bubbles. Proceedings of the National Academy of Sciences of the United States of America, 111(52).

LiCalzi, M., \& Surucu, O. (2012). The power of diversity over large solution spaces. Management Science, 58(7), 1408-1421.

Lorenz, J., Rauhut, H., Schweitzer, F., \& Helbing, D. (2011). How social influence can undermine the wisdom of crowd effect. Proceedings of the National Academy of Sciences of the United States of America, 108(22), 9020-5.

Lowery, B. S., Unzueta, M. M., Knowles, E. D., \& Goff, P. A. (2006). Concern for the in-group and opposition to affirmative action. Journal of Personality and Social Psychology, 90(6), 961-974.

Loyd, D. L., Wang, C. S., Phillips, K. W., \& Lount, R. B. (2012). Social category diversity promotes premeeting elaboration: The role of relationship focus. Organization Science, 7039, $1-16$.

Luce, R. D., \& Raiffa, H. (1957). Games and Decisions. New York.

Mannix, E., \& Neale, M. (2005). What differences make a difference? The promise and reality of diverse teams in organizations. Psychological Science in the Public Interest, 6(2), 31-55.

March, J. G., \& Simon, H. A. (1958). Organizations. New York: John Wiley and Sons.

Mas-Collel, A., Whinston, M., \& Green, J. (1995). Microeconomic Theory. Oxford University Press.

McGinn, K. L., \& Milkman, K. L. (2012). Looking Up and Looking Out: Career Mobility Effects of Demographic Similarity Among Professionals. Organization Science, 7039, 1-20. 
Milkman, K. L., Chugh, D., \& Bazerman, M. H. (2009). How can decision making be improved? Perspectives on Psychological Science, 4(4), 379-383.

Mochon, D., \& Frederick, S. (2013). Anchoring in sequential judgments. Organizational Behavior and Human Decision Processes, 122(1), 69-79.

Mohr, J., \& Spekman, R. (1994). Characteristics of partnership success: Partnership attributes, communication behavior, and conflict resolution techniques. Strategic Management Journal, 15(June 1993), 135-152.

Moore, D. A. (1999). Order effects in preference judgments: Evidence for context dependence in the generation of preferences. Organizational Behavior and Human Decision Processes, 78(2), $146-165$.

Niederle, M., Segal, C., \& Vesterlund, L. (2013). How costly is diversity? Affirmative action in light of gender differences in competitiveness. Management Science, 59(1), 1-16.

Nisbett, R. E., \& Wilson, T. D. (1977). The Halo Effect: Evidence for Unconscious Alteration of Judgments. Journal of Personality and Social Psychology, 35(4), 250-256.

Northcraft, G. B., \& Neale, M. A. (1987). Experts, amateurs, and real estate: An anchoring-and-adjustment perspective on property pricing decisions. Organizational Behavior and Human Decision Processes, 39(1), 84-97.

Page, S. E. (2007a). Making the difference: Applying a logic of diversity. The Academy of Management Perspectives, (pp. 6-21).

Page, S. E. (2007b). The difference: How the power of diversity creates better groups, firms, schools, and societies. Princeton, New Jersey: Princeton University Press.

Phillips, K., \& Loyd, D. (2006). When surface and deep-level diversity collide: The effects on dissenting group members. Organizational Behavior and Human Decision Processes, 99, $143-160$.

Phillips, K., Mannix, E., Neale, M. A., \& Gruenfeld, D. H. (2004). Diverse groups and information sharing: The effects of congruent ties. Journal of Experimental Social Psychology, 40, 497-510.

Phillips, K. W., \& Apfelbaum, E. P. (2012). Delusions of homogeneity? Reinterpreting the effects of group diversity. In M. A. Neale, \& E. A. Mannix (Eds.) Looking Back, Moving Forward: A Review of Group and Team-Based Research, (pp. 185-207). Emerald Group Publishing Limited.

Phillips, K. W., Northcraft, G. B., \& Neale, M. A. (2006). Surface-level diversity and decision-making in groups: When does deep-level similarity help? Group Processes \& Intergroup Relations, 9(4), 467-482.

Phillips, L. T., Weisbuch, M., \& Ambady, N. (2014). People perception: Social vision of groups and consequences for organizing and interacting. Research in Organizational Behavior, 34, $101-127$. 
Rispens, S., Greer, L., Jehn, K. A., \& Thatcher, S. M. B. (2011). Not so bad after all: How relational closeness buffers the association between relationship conflict and helpful and deviant group behaviors. Negotiation and Conflict Management Research, 4(4), 277-296.

Schkade, D., \& Kahneman, D. (1998). Does living in California make people happy? A focusing illusion in judgments of life satisfaction. Psychological Science, (pp. 340-346).

Sesko, A. K., \& Biernat, M. (2010). Prototypes of race and gender: The invisibility of Black women. Journal of Experimental Social Psychology, 46(2), 356-360.

Shemla, M., Meyer, B., Greer, L. L., \& Jehn, K. A. (2016). A review of perceived diversity in teams: Does how members perceive their team's composition impact on team processes and outcomes? Journal of Organizational Behavior.

Simmons, J. P., LeBoeuf, R. A., \& Nelson, L. D. (2010). The effect of accuracy motivation on anchoring and adjustment: do people adjust from provided anchors? Journal of Personality and Social Psychology, 99(6), 917-32.

Simmons, J. P., Nelson, L. D., \& Simonsohn, U. (2011). False-positive psychology: Undisclosed flexibility in data collection and analysis allows presenting anything as significant. Psychological Science, 22(11), 1359-66.

Simon, H. A. (1955). A behavioral model of rational choice. The Quarterly Journal of Economics, 69(1), 99-118.

Staats, B. R., Milkman, K. L., \& Fox, C. R. (2012). The team scaling fallacy: Underestimating the declining efficiency of larger teams. Organizational Behavior and Human Decision Processes, 118(2), 132-142.

Thaler, R. H., \& Sunstein, C. R. (2008). Nudge: Improving Decisions About Health, Wealth, and Happiness. Penguin Books.

Thomas, D., \& Ely, R. (1996). Making differences matter. Harvard Business Review, (September-October).

Tor, A., \& Bazerman, M. (2003). Focusing failures in competitive environments: Explaining decision errors in the Monty Hall game, the acquiring a company problem, and multiparty ultimatums. Journal of Behavioral Decision Making, 374(September), 353-374.

Tversky, A., \& Gati, I. (1982). Similarity, separability, and the triangle inequality. Psychological review, 89(2), 123-54.

Tversky, A., \& Kahneman, D. (1974). Judgment under uncertainty: Heuristics and biases. Science, 185(4157), 1124-31.

Unzueta, M. M., \& Binning, K. R. (2012). Diversity is in the eye of the beholder: How concern for the in-group affects perceptions of racial diversity. Personality and Social Psychology Bulletin, 38(1), 26-38. 
Unzueta, M. M., Knowles, E. D., \& Ho, G. C. (2012). Diversity is what you want it to be: How social-dominance motives affect construals of diversity. Psychological Science, 23(3), 303-9.

Van den Steen, E. (2010). Culture clash: The costs and benefits of homogeneity. Management Science, 56(10), 1718-1738.

van Dijk, H., van Engen, M. L., \& van Knippenberg, D. (2012). Defying conventional wisdom: A meta-analytical examination of the differences between demographic and job-related diversity relationships with performance. Organizational Behavior and Human Decision Processes, $119(1), 38-53$.

van Knippenberg, D., De Dreu, C. K. W., \& Homan, A. C. (2004). Work group diversity and group performance: an integrative model and research agenda. The Journal of applied psychology, 89(6), 1008-22.

van Knippenberg, D., \& Schippers, M. C. (2007). Work group diversity. Annual Review of Psychology, 58, 515-41.

von Neumann, J., \& Morgenstern, O. (1947). Theory of Games and Economic Behavior. Princeton, New Jersey: Princeton University Press.

Wang, L., \& Murnighan, J. K. (2013). The generalist bias. Organizational Behavior and Human Decision Processes, 120(1), 47-61.

Williams, K., \& O'Reilly, C. (1998). Demography and diversity in organizations: A review of 40 years of research. Research in Organizational Behavior, 20, 77-140.

Wilson, T. D., \& Brekke, N. (1994). Mental contamination and mental correction: unwanted influences on judgments and evaluations. Psychological Bulletin, 116(1), 117-142.

Wuchty, S., Jones, B. F., \& Uzzi, B. (2007). The increasing dominance of teams in production of knowledge. Science, 316(5827), 1036-9.

Zellmer-Bruhn, M. E., Maloney, M. M., Bhappu, A. D., \& Salvador, R. B. (2008). When and how do differences matter? An exploration of perceived similarity in teams. Organizational Behavior and Human Decision Processes, 107(1), 41-59. 

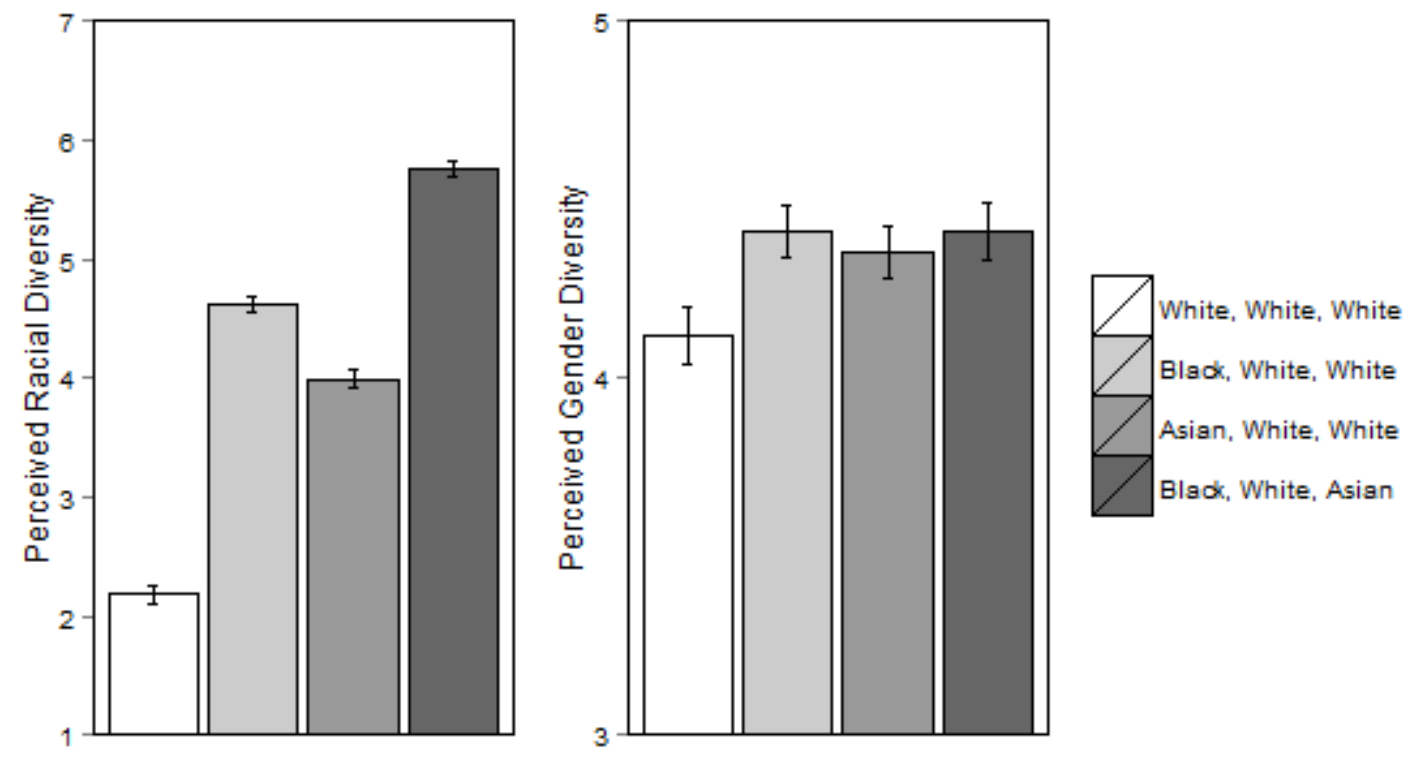

Figure 1. Causal effects of objective racial diversity on perceived racial diversity (left) and perceived gender diversity (right, demonstrating a spillover bias), from Experiment 1. Error bars are standard errors. 

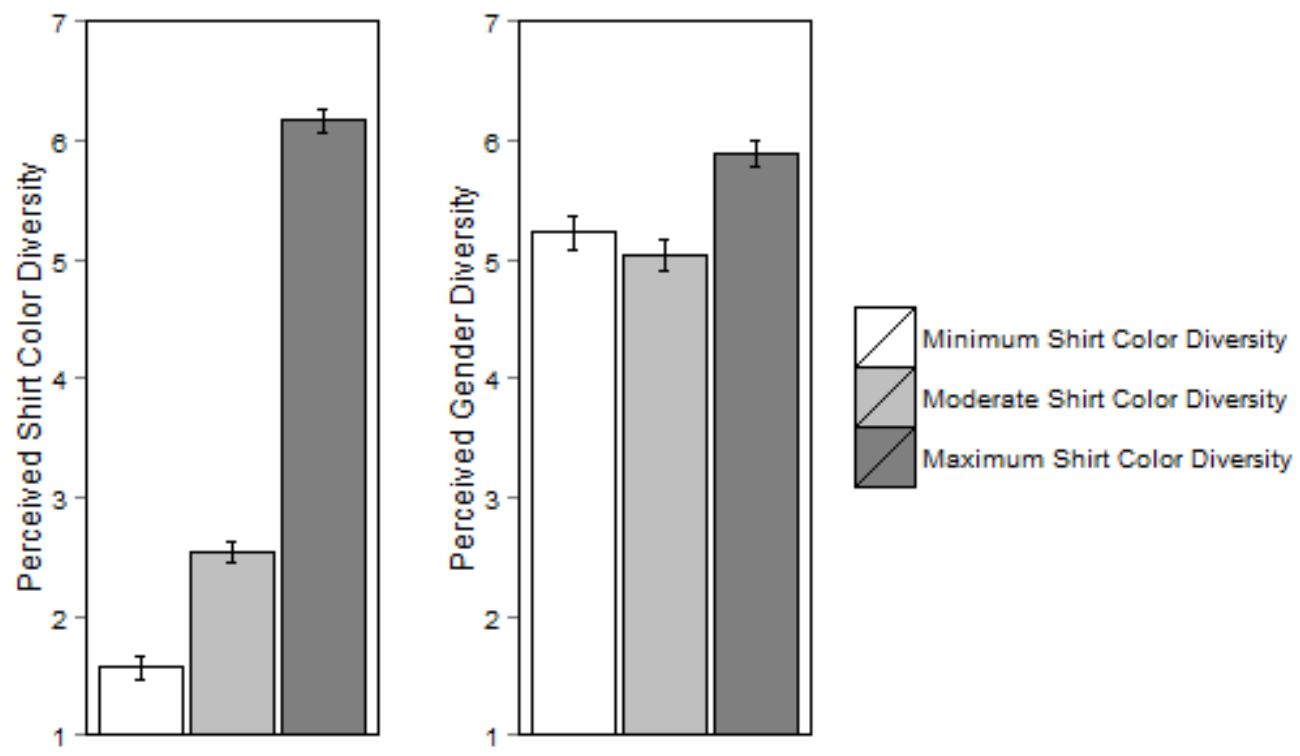

Figure 2. Causal effects of objective shirt color diversity on perceived shirt color diversity (left) and perceived gender diversity (right, demonstrating a spillover bias), from Experiment 2. Error bars are standard errors. 


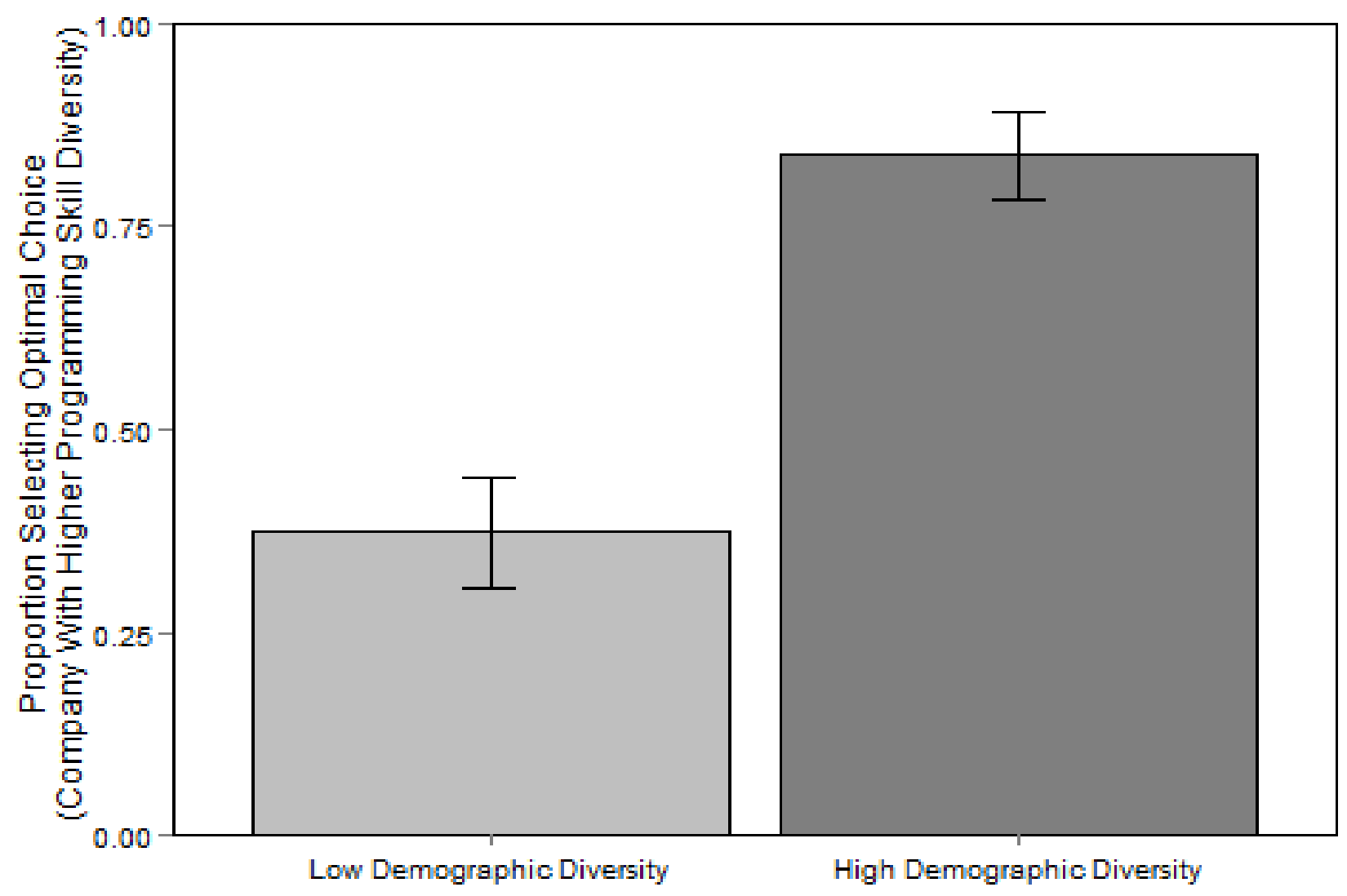

Figure 3. Causal effect of level of demographic diversity of optimal company on the proportion of participants who selected the optimal company to acquire (i.e. who correctly chose to acquire the company with higher programming skill diversity), from Experiment 3. Error bars are standard errors. 